\title{
Generating a Domain Specific Checklist through an Adaptive Framework for Evaluating Social Networking Websites
}

\author{
Roobaea AlRoobaea \\ Faculty of Computing and \\ Information Technology, \\ Taif University, Saudi Arabia, \& \\ School of Computing \\ Sciences, University of East Anglia \\ Norwich, UK
}

\begin{abstract}
The growth of the Internet and related technologies has enabled the development of a new breed of dynamic websites and applications that are growing rapidly in use and that have had a great impact on many businesses. These websites need to be continuously evaluated and monitored to measure their efficiency and effectiveness, to assess user satisfaction, and ultimately to improve their quality.
\end{abstract}

The lack of an adaptive usability evaluation checklist for improvement of the usability assessment process for social network sites (SNSs) represents a missing piece in usability testing. This paper presents an adaptive Domain Specific Inspection (DSI) checklist as a tool for evaluating the usability of SNSs. The results show that the adaptive social network usability checklist helped evaluators to facilitate the evaluation process, and it helped website owners to choose the specific-context usability areas that they feel are important to their usability evaluations. Moreover, it was more efficient and effective than user testing and heuristics evaluation methods.

Keywords-Heuristic evaluation (HE); User Testing (UT); Domain Specific Inspection (DSI); social networks domain; social networks checklist

\section{INTRODUCTION}

It is clear that Heuristic Evaluation (HE) and User Testing (UT) are the most important traditional usability evaluation methods for ensuring system quality and usability [1;2]. Currently, complex computer systems, mobile devices and their applications have made usability evaluation methods more critical; however, usability differs from one product to another depending on product characteristics. It is clear that users have become the most important factor impacting on the success of a product; if a product is produced and is then deemed not useful by the end-users, it is a failed product; nobody can use it and the company cannot make money [3]. [4] asserted, "companies are endeavoring to understand both user and product, by investigating the interactions between them".

Traditional usability measures of effectiveness, efficiency and satisfaction are not adequate for the new contexts of use [5]. HE has been claimed to be too general and too vague for evaluating new products and domains with different goals; HE can produce a large number of false positives, and it is unlikely to encompass all the usability attributes of user experience and design in modern interactive systems [6;7]. UT has been claimed to be costly, time consuming, prone to missing consistency problems and subject to environmental factors [8]. To address these challenges, many frameworks and models have been published to update usability evaluation methods (UEMs) [9; 10]; however, these frameworks and models are not applicable to all domains because they were developed to deal with certain aspects of usability in certain areas [11].

The adaptive framework was originally constructed and then the DSI method and its checklist for educational domain was generated and evaluated against HE and UT methods [12; 13]. For further validation of the adaptive framework, social networks domain was chosen and then the DSI method was generated for SNSs and it evaluated against HE and UT methods [14]; in those experiences, the DSI method delivered interesting results by discovering more real usability problems in specific usability areas than HE method or UT method. An adaptive checklist based upon the DSI method for facilitating the social network sites evaluation process was developed. The main objective of this paper is to address the challenges that were raised and to present this checklist which can be applied to any website in the social network domain as a tool that can be used by designers, developers, instructors, and website owners to design an interactive interface or assess the quality of existing website. It also allows anyone to adopt any area of usability or any principle to determine the usability problems related to the seven specific areas in social network sites.

This paper is organized in the following way. Section 2 starts with a brief literature review, including a summary of the adaptive framework. Section 3 highlights the research methodology followed in this research. Section 4 presents a discussion of the findings. Section 5 presents the conclusion and future work.

\section{LITERATURE REVIEW}

\section{A. Background and Motivation}

The primary concern of interaction design is to develop interactive products or technologies that are usable. A website 
is a product, and the quality of a product takes a significant amount of time and effort to develop. Web design is a key factor in determining the success of any website, and users should be the priority in the designers' eyes because usability problems in a website can have serious ramifications, over and above the users failing to meet their needs [15]. A high-quality product is one that provides all the main functions in a clear format, and that offers good accessibility and a simple layout to avoid users spending more time learning how to use it than satisfying their needing; these are the fundamentals of the 'usability' of a product. Poor product usability may have a negative impact on various aspects of the organization, and may not allow users to achieve their goals efficiently, effectively and with a sufficient degree of satisfaction. The website consultants and marketing sectors have understood that the number of hits, customer return rate, and customer satisfaction are extremely affected by the usability of a website [16].

The success of SNSs has gained a great deal of attention of researchers in latest years. Because, the impact of these sites on business is still largely unexplored. For example, impact SNSs on knowledge management (e.g. customer relationship management), collaboration, communication, innovation, and training [17; 18]. Currently, companies, educational systems and governments adopt SNSs tools to their environment work to save time, make money and to improve their corporate productivity.

In this regards, designing interactive websites and evaluating them are common stages of product development. On the other hand, the current traditional usability methods to measure quality attributes, such as, effectiveness, efficiency and satisfaction are not adequate for the new contexts of use, and are not stable in the modern dynamic environment such as SNSs and e-catalogs systems [19;20]. Consequently, several studies have emphasized the importance of developing new kinds of usability evaluation methods and of constantly improving and making modifications to existing methods as a matter of priority, in order to increase their effectiveness [21]. Having extensively reviewed the existing literature on web usability evaluation methods; this research is unique in systematically constructing an adaptive framework that is applicable across numerous domains. This DSI framework generates DSI checklist as available tool for assessing and improving the usability of a product.

\section{B. Description of the Adaptive Framework}

The adaptive framework was developed according to an established methodology in HCI research [12; 22]. It consists of four development steps as follows:

Development Step One (D1: Familiarization): This stage starts by justifying the need to develop a method that is specific, productive, useful, usable, reliable and valid, which can be used to evaluate an interface design in the chosen domain. It entails reviewing all the published material in the area of UEMs but with a specific focus on knowledge of the chosen domain. Also, it seeks to identify an approach that would support developers and designers in thinking about their design from the intended end-users' perspective.
Development Step Two (D2: User Input): This stage consists of mini-user testing (task scenarios, think aloud protocol and questionnaire). Users are asked to perform a set of tasks on a typical domain website and then asked to fill out a questionnaire. The broad aim of this stage is to elicit feedback on a typical system from real users in order to appreciate the user perspective, to identify requirements and expectations and to learn from their errors. Understanding user needs has long been a key part of user design, and so this step directly benefits from including the advantages of user testing.

Development Step Three (D3: Expert Input): This stage aims to consider what resources are available for addressing the need. These resources, such as issues arising from the mini-user testing results and the literature review, require a discussion amongst experts (in the domain and/or usability) in order to obtain a broader understanding of the specifics of the prospective domain. Also, it entails garnering more information through conversations with expert evaluators to identify the areas/classification schemes of the usability problems related to the selected domain from the overall results. These areas provide designers and developers with insight into how interfaces can be designed to be effective, efficient and satisfying; they also support more uniform problem description and they can guide expert evaluators in finding real usability problems, thereby facilitating the evaluation process by judging each area and page in the target system.

Development Step Four (D4: Draw Up DSI: data analysis): The aim of this step is to analyse all the data gathered from the previous three. Then, the DSI method will be established (as guidelines or principles) in order to address each area of the selected domain.

\section{Description of validation process for the Adaptive Framework}

After constructing the DSI framework, the researchers test it intensively through rigorous validation methods to verify the extent to which it achieves the identified goals, needs and requirements that the method was originally developed to address. The validation process of the DSI checklist included analytical test, empirical test and statistical test. These tests were conducted using the newly developed DSI checklist alongside heuristics evaluation (HE), user testing (UT) and SPSS package.

\section{RESEARCH METHODOLOGY}

\section{A. Evaluation of the Practicality of the Framework}

In the first stage, the researchers conducted a literature review on the materials relating to usability and UEMs as well as on the requirements of social network sites (SNSs). In stage two, a mini-user testing session was conducted through a brief questionnaire that entailed four tasks, which were sent to ten users who are regular SNS users, to gain an appreciation of which elements or features they expect to be in any SNS, their more general expectations of these sites and to learn from their errors. 
In stage three, a focus group discussion session was conducted with experts in usability and/or the SNS domain (i.e. single and double experts). Cohen's kappa coefficient was used on the same group twice to enable a calculation of the reliability quotient for identifying usability problem areas. In stage four, the researchers analysed the results of the three stages and incorporated the findings. The intra-observer testretest using Cohen's kappa yielded a reliability value of 0.9 , representing satisfactory agreement between the two rounds. After that, the usability problems areas were identified to facilitate the process of evaluation and analysis, and to help designers and programmers to identify the areas in their website that need improvement. Then, the DSI method was established. It is common for social networks as well as business networking websites to take into account what is called 'user experience'. The DSI method was classified according to the usability problem areas, and checklist was developed, as shown in Appendix A.

\section{B. Selection of the targeted websites}

The first step in an initial preparation phase is selecting the websites. The researchers sought to ensure that the selected websites would support the research goals and objectives. The selection process was criteria-based; five aspects were determined and verified for each website, and these are: 1) Good interface design, 2) Rich functionality, 3) Good representatives of the social network domain, 4) Not familiar to the users, 5) No change will occur before and during the actual evaluation. In order to achieve a high level of quality in this research, the researchers chose three well-known websites in this domain, which are LinkedIn, Google+ and Ecademy. All of these have all the aspects mentioned above.

\section{Recruitment of Experts and Users}

The selection of usability experts and users is the second important step in the initial preparation phase in this experiment. The researchers decided to recruit six expert evaluators, divided into two groups of three, who were carefully balanced in terms of experience. In each group, there are two double expert evaluators (usability specialists in SNSs) and one single expert evaluator (usability specialists in general). Each group employed two methods, namely DSI checklist and HE, to evaluate the three different websites. The evaluation was carried out in a prescribed sequence, i.e. Group 1 used DSI checklist on Google+ and then HE on LinkedIn, and finally DSI checklist on Ecademy, while Group 2 used HE on Google+ and Ecademy and then DSI checklist on LinkedIn. The researchers adopted this technique to avoid any bias in the results and also to avoid the risk of any expert reproducing his/her results in the second session through over-familiarity with one set of heuristics, i.e. each evaluation was conducted with a fresh frame of mind.

Selecting and recruiting users must be done carefully; the participants must reflect the real users of the targeted website because inappropriate users will lead to incorrect results, thereby invalidating the test. Appropriate users will deliver results that are more reliable; they will also be encouraged to conduct the experiment [30]. There is no agreement on how many users should be involved in usability testing. [30] suggested that 6 to 12 users are sufficient for testing, whereas other studies have recommended that 7, 15 and 20 users are the optimal numbers for evaluating small or large websites; particularly 20 users if benchmarking is needed [31]. At this point, 30 users were engaged; they were chosen carefully to reflect the real users of the targeted websites and were divided into three groups for each website, i.e. a total of 10 users for each website. The majority of the users are students and employees, and they were mixed across the three users groups in terms of gender, age, and education level and computer skills.

\section{Piloting the Adaptive Checklist}

A pilot study was conducted by two independent evaluators. They checked the adaptive DSI checklist by applying it in a real experiment to make sure that there were no spelling or grammatical errors and no ambiguous words or phrases, and that all of the sentences in the adaptive checklist were sufficiently clear to be used by the evaluators. A fewer minor improvements were made,

\section{E. Actual Evaluation}

The Heuristics Validation phase started with a training (familiarization) session for the six expert evaluators. They were given a UEM training pack that contained exactly the same information for both groups, except for the information pertaining to their respective UEM. The researchers emphasized to each evaluator groups that they should apply a lower threshold before reporting a problem in order to avoid misses in identifying real problems in the system. Then, the actual expert evaluation was conducted and the evaluators evaluated all websites consecutively, rating all the problems they found in a limited time (which was 90 minutes). After that, they were asked to submit their evaluation report and to complete a five-point scale on an SUS questionnaire (1 for strongly disagree and 5 for strongly agree) to rate their satisfaction on the evaluation method they had used (DSI checklist or HE), and to give feedback on their own evaluation results.

The Testing Validation phase started with a training (familiarization) session for the 60 users; it involved a quick introduction on the task designs, the think-aloud approach and the purpose of the study. The next step entailed explaining the environment and equipment, followed by a quick demonstration on how to 'think aloud' while performing the given tasks. Prior to the tests, the users were asked to read and sign the consent letter, and to fill out a demographic data form that concluded details such as level of computer skill. All the above steps took approximately ten minutes for each test session. The actual test started from this point, i.e. when the user was given the task scenario sheet and asked to read and then perform one task at a time. Once they had finished the session, they were asked to rate their satisfaction score relating to the tested website, to write down their comments and thoughts, and to explain any reaction that had been observed during the test, all in a feedback questionnaire. This was followed by a brief discussion session.

\section{DISCUSSION AND FINDINGS}

The researchers extracted the problems discovered by the three methods from the problems sheet and removed all false 
positive problems, subjective problems, and duplicated problems during the debriefing session. The problems agreed upon were merged into a unique master problem list (see Table 1, Table 2, and Table 3), and any problems upon which the evaluators disagreed were removed.

TABLE I. Total Problems Found (Without DuplicAtes) IN GOOGLE+

\begin{tabular}{|c|c|c|c|c|}
\hline $\begin{array}{r}\text { Method } \\
\text { Problem type }\end{array}$ & UT & HE & $\begin{array}{c}\text { DSI } \\
\text { checklist }\end{array}$ & $\begin{array}{l}\text { Total } \\
\text { problems }\end{array}$ \\
\hline Catastrophic & $4(100 \%)$ & $0(0 \%)$ & $0(0 \%)$ & 4 \\
\hline Major & $9(82 \%)$ & $3(27 \%)$ & $11(100 \%)$ & 11 \\
\hline Minor & $11(37 \%)$ & $13(43 \%)$ & $28(93 \%)$ & 30 \\
\hline Cosmetic & $10(37 \%)$ & $6(22 \%)$ & $16(59 \%)$ & 27 \\
\hline $\begin{array}{l}\text { No. of } \\
\text { problems }\end{array}$ & $34(47 \%)$ & $22(31 \%)$ & $55(75 \%)$ & 72 \\
\hline
\end{tabular}

TABLE II. TOTAL PROBLEMS FOUND (WITHOUT DUPLICATES) IN LINKEDIN

\begin{tabular}{|c|c|c|c|c|}
\hline $\begin{array}{c}\text { Method } \\
\text { Problem type }\end{array}$ & UT & HE & $\begin{array}{c}\text { DSI } \\
\text { checklist }\end{array}$ & $\begin{array}{l}\text { Total } \\
\text { problems }\end{array}$ \\
\hline Catastrophic & $2(33 \%)$ & $0(0 \%)$ & $6(100 \%)$ & 6 \\
\hline Major & $5(39 \%)$ & $5(39 \%)$ & $11(85 \%)$ & 13 \\
\hline Minor & $8(32 \%)$ & $8(32 \%)$ & $19(76 \%)$ & 25 \\
\hline Cosmetic & $11(92 \%)$ & $0(0 \%)$ & $11(92 \%)$ & 12 \\
\hline No. of problems & $26(46 \%)$ & $13(23 \%)$ & $47(84 \%)$ & 56 \\
\hline
\end{tabular}

TABLE III. TOTAL PROBLEMS FOUND (WITHOUT DUPLICATES) IN ECADEMY

\begin{tabular}{|c|c|c|c|c|}
\hline $\begin{array}{r}\text { Method } \\
\text { Problem type }\end{array}$ & UT & HE & $\begin{array}{c}\text { DSI } \\
\text { checklist }\end{array}$ & $\begin{array}{l}\text { Total } \\
\text { problems }\end{array}$ \\
\hline Catastrophic & $0(0 \%)$ & $0(0 \%)$ & $0(0 \%)$ & 0 \\
\hline Major & $3(50 \%)$ & $0(0 \%)$ & $6(100 \%)$ & 6 \\
\hline Minor & $6(50 \%)$ & $8(67 \%)$ & $11(92 \%)$ & 12 \\
\hline Cosmetic & $11(37 \%)$ & $4(13 \%)$ & $16(53 \%)$ & 30 \\
\hline No. of problems & $19(40 \%)$ & $12(25 \%)$ & $33(69 \%)$ & 48 \\
\hline
\end{tabular}

Overall, UT, HE and adaptive DSI checklist revealed different types and numbers of usability problems. One-way ANOVA reveals that there is significant difference between the three methods in terms of discovering usability problems on the whole $(\mathrm{F}=13.32, \mathrm{p}<0.001)$. UT, HE and DSI revealed $47 \%, 31 \%$ and $75 \%$ of the usability problems found in Google+, respectively. One-way ANOVA-Tukey HSD was used and the results show that there is a strongly significant mean difference amongst the methods in finding usability problems in Google+ between HE and UT, where $\mathrm{p}<0.03$ and the mean difference $=-14.667$, as well as between DSI checklist and HE, where $p<0.003$ and mean difference = 16.767. In LinkedIn, UT, HE and DSI checklist revealed 46\%, $23 \%$ and $84 \%$ of the found usability problems, respectively. One-way ANOVA-Tukey HSD was used and the results show that there is a strongly significant difference amongst the methods in finding usability problems in LinkedIn, particular between HE and DSI checklist ( $\mathrm{p}<0.046$ and mean difference $=-14.333)$ and between HE and UT ( $p<0.009$ and mean difference $=-15.367)$. Finally, UT, HE and DSI checklist revealed $50 \%, 32 \%$ and $87 \%$ of the found usability problems in Ecademy, respectively. One- way ANOVA-Tukey HSD was used and the results show that there is significant difference amongst the methods in finding usability problems in Ecademy between HE and DSI checklist, where $\mathrm{p}=0.012$ and mean difference $=-15.000$. The performance of HE in discovering usability problems during the experiment ranged from $23 \%$ to $31 \%$. UT discovered usability problems ranging from $40 \%$ to $47 \%$, while DSI checklist discovered usability problems ranging from $69 \%$ to $84 \%$. Also, UT and HE performed better in discovering major, minor and cosmetic real usability problems, but DSI checklist was the best in discovering more catastrophic, major, minor and cosmetic real usability problems. Thus, it can be seen that DSI checklist was the best in discovering real problems; this was followed by UT, and then finally HE.

Furthermore, each method revealed different types of problem (both unique and overlapping). For example, DSI checklist found $41 \%$ uniquely of the total number of real usability problems $(\mathrm{n}=73$ out of 176). HE found $14 \%$ uniquely of the total number of real usability problems $(n=24$ out of 176), and UT identified $32 \%$ uniquely of the total number of real usability problems $(\mathrm{n}=56$ out of 176). 23 (13\%) real problems out of 176 were found to be 'overlapping' by the three methods. In terms of the definition of missed problems given by [25], we can consider that the problems that were found by one method but not found by the others to be missed problems. From this point, DSI checklist missed 80 real usability problems; however, HE and UT missed 129 and 97 real usability problems, respectively. These findings should facilitate any decision-making with regard to which of these methods to employ, either on its own or in combination with another, in order to identify usability problems on social websites.

\section{CONCLUSION AND FUtURE WORK}

The main aim of this experiment was to evaluate the adaptive DSI checklist for the social network websites through its ability to discover usability problems by comparing its results with usability testing (UT) and Heuristic Evaluation (HE). The adaptive DSI checklist was built based on the views of users and usability experts. It seemed to guide the evaluators' thoughts in judging the usability of the website through clear principles that include all aspects of the social networks' quality, which was represented in the seven usability areas.

Also, the DSI checklist outperformed both HE and UT, even when taken together. This finding facilitates decisionmaking with both regard to which of these methods to employ. Also, it addresses the shortcomings of these methods; hence, to avoid wasting money and time, an alternative method that is well-developed, context-specific and adaptive checklist to the situation in hand, such as what has been generated here and for the educational domain in [13], should be employed. This research contributes to the advancement of knowledge in the HCI field by introducing the adaptive DSI checklist that is specific for evaluating the social network websites. In order to consolidate and confirm the findings, future research could include testing the adaptive DSI checklist by applying it on different SNSs for example. Also, we need to further test the adaptive framework by developing an adaptive DSI checklist for different fields, such as e-commerce or news sites. 


\section{ACKNOWLEDGEMENTS}

We thank Hani S. Alghamdi, the expert evaluators and users in the School of Computing Sciences at the University Of East Anglia (UEA) and the Aviva Company for their participation in the comparative study and the mini-usability testing.

\section{References}

[1] G. Lindgaard and J. Chattratichart, "Usability testing: what have we overlooked?" in Proceedings of the SIGCHI conference on Human Factors in Computing Systems, pp. 1415-1424, ACM, 2007.

[2] J. Chattratichart and J. Brodie, "Applying user testing data to UEM performance metrics", in CHI'04 extended abstracts on Human Factors in Computing Systems, pp. 1119-1122, ACM, 2004.

[3] J. Nielsen, "Did poor usability kill e-commerce", in www.useit.com, 2001.

[4] F. Nayebi, J.-M. Desharnais and A. Abran, "The state of the art of mobile application usability evaluation", in Electrical \& Computer Engineering (CCECE), $201225^{\text {th }}$ IEEE Canadian Conference on, pp. 14, IEEE, 2012.

[5] P. Zaharias and A. Poylymenakou, "Developing a usability evaluation method for e-learning applications: Beyond functional usability", Intl. Journal of Human-Computer Interaction, vol. 25, no. 1, pp. 75-98, 2009.

[6] M. Hertzum and N. Jacobsen, "The evaluator effect: A chilling fact about usability evaluation methods", International Journal of HumanComputer Interaction, vol. 13, no. 4, pp. 421-443, 2001.

[7] J. Chattratichart and G. Lindgaard, "A comparative evaluation of heuristic-based usability inspection methods," in CHI, vol. 8, pp. 05-10, 2008.

[8] A. Oztekin, Z. J. Kong and O. Uysal, "Uselearn: A novel checklist and usability evaluation method for e-learning systems by criticality metric analysis", International Journal of Industrial Ergonomics, vol. 40, no. 4, pp. 455-469, 2010.

[9] N. Alias, S. Siraj, D. DeWitt, M. Attaran and A. B. Nordin, "Evaluation on the usability of physics module in a secondary school in Malaysia: Students retrospective", The Malaysian Online Journal of Educational Technology, p. 44, 2013.

[10] C. Gutwin and S. Greenberg, "The mechanics of collaboration: Developing low cost usability evaluation methods for shared workspaces", in Enabling Technologies: Infrastructure for Collaborative Enterprises, 2000 (WET ICE 2000). Proceedings IEEE $9^{\text {th }}$ International Workshops, pp. 98-103, IEEE, 2000.

[11] C. K. Coursaris and D. J. Kim, "A meta-analytical review of empirical mobile usability studies", Journal of Usability Studies, vol. 6, no. 3, pp. 117-171, 2011.
[12] R. AlRoobaea, A. Al-Badi, P. Mayhew. " Generating a Domain Specific Inspection Evaluation Method through an Adaptive Framework: A Comparative Study on Educational Websites. " International Journal of Human Computer Interaction (IJHCI), 4(2), 88, 2013.

[13] R. AlRoobaea, A. Al-Badi, P. Mayhew, "Generating an Educational Domain Checklist through an Adaptive Framework for Evaluating Educational Systems." International Journal of Advanced Computer Science and Applications(IJACSA), 4(8), 2013.

[14] R. AlRoobaea, A. Al-Badi, P. Mayhew. "A framework for generating a domain specific inspection evaluation method: A comparative study on social networking websites." In Science and Information Conference (SAI), 2013, pp. 757-767. IEEE, 2013.

[15] S. Y. Chen and R. D. Macredie, "The assessment of usability of electronic shopping: A heuristic evaluation", International Journal of Information Management, vol. 25, no. 6, pp. 516-532, 2005.

[16] Y. Rogers, H.Sharp, and J.Preece," Interaction design: beyond humancomputer interaction," Wiley, 2007.

[17] F. Bonchi, C. Castillo, A. Gionis, and A. Jaimes," Social network analysis and mining for business applications," ACM Transactions on Intelligent Systems and Technology (TIST), 2(3), 22, 2011.

[18] S. Andriole, "Business impact of Web 2.0 technologies," Communications of the ACM, 53(12), 67-79, 2010.

[19] A. Thompson and E. Kemp, "Web 2.0: extending the framework for heuristic evaluation", in Proceedings of the $10^{\text {th }}$ International Conference NZ Chapter of the ACM's Special Interest Group on Human-Computer Interaction, pp. 29-36, ACM, 2009.

[20] A. Alrobai, R. AlRoobaea, A. Al-Badi, P. Mayhew. "Investigating the usability of e-catalogue systems: modified heuristics vs. user testing." Journal of Technology Research, 2012.

[21] Y. Guo, R. Proctor and G. Salvendy,"A conceptual model of the axiomatic usability evaluation method," Human Interface and the Management of Information, Interacting with Information, pp. 93-102, 2011.

[22] R. AlRoobaea, A. Al-Badi, P. Mayhew , "Generating a Domain Specific Inspection Evaluation Method through an Adaptive Framework." International Journal of Advanced Computer Science and Applications(IJACSA), 4(6), 2013.

[23] J. Dumas, and J. Redish, A practical guide to usability testing. Intellect Ltd, 1999.

[24] J. Nielsen, and H. Loranger, Prioritizing web usability, New Riders Press, Thousand Oaks, CA, USA,2006.

[25] L. Masip, T. Granollers and M. Oliva, "A heuristic evaluation experiment to validate the new set of usability heuristics," In Proceedings of the 2011 Eighth International Conference on Information Technology: New Generations, pages 429-434. IEEE Computer Society,2011. 
APPENDIX A: THE ADAPTIVE DOMAIN SPECIFIC INSPECTION CHECKLIST FOR EVALUATING SOCIAL NETWORK WEBSITES USABILITY

\begin{tabular}{|c|c|}
\hline Usability problem area & The adaptive Domain Specific Inspection (DSI) checklist \\
\hline & $\begin{array}{l}\text { Design consistency: } \\
\text { O Are all links and button styles throughout the site consistent? } \\
\text { A Are all the pages organized /structured in a similar style? } \\
\text { Are the font choices, colours and sizes consistent with good user screen design? } \\
\text { Is the navigation of the site consistent? } \\
\text { O Does site has access to Home, Contact Us and other relevant information link on all the pages? }\end{array}$ \\
\hline Layout and formatting (LF) & $\begin{array}{l}\text { Simple user interface: } \\
\text { O Does the site provide brief, constructive, unambiguous descriptions of the task? } \\
\text { O Are the most important items in a list placed at the top? } \\
\text { O Does site have search \& help option? } \\
\text { O Does the site use minimal page scrolling (i.e. the pages are not too long)? } \\
\text { O Does the site highlight important changes (i.e. most viewed, most discussed, favourite feeds and recent updates)? } \\
\text { } \text { Does the site use glyphs and icons (metaphors) for representation and recognition in a context that is relevant, and not } \\
\text { just for decoration? } \\
\text { O Does the site use alternative text for the graphics/images? } \\
\text { Does the site categorize content into primary (absolutely necessary to show) and secondary (can be hidden), and show } \\
\text { secondary information only on user demand? } \\
\text { Is the site layout, and architecture logical and hierarchical } \\
\text { Does the colour scheme override the content (undesirable)? } \\
\text { O Is the site easily readable? } \\
\text { Does the site make important keys larger than other keys? } \\
\text { O Are pages easy to bookmark? Is it possible to bookmark a person? } \\
\text { Is a casual user able to return to using the site after some period without having to learn everything all over again? Are } \\
\text { all functions and information well-presented and easy to remember? } \\
\text { O Is the screen layout efficient and visually pleasing? } \\
\text { O Does the site provide the minimum number of clickable actions, selections and scrolling to complete one main task? } \\
\text { O Is the site constantly used pop-up windows? } \\
\text { O Can users switch between windows during overlapping windows? } \\
\text { O Are users allowed to move backward, forward and skip data entry screens among all the pages? } \\
\text { O Do all pages have a title? } \\
\text { O Does the site helps user to pre populate data during registration, search etc.? }\end{array}$ \\
\hline \multirow{5}{*}{ Content quality (CQ) } & $\begin{array}{l}\text { Correct, relevant, up to date and reliable information: } \\
\text { Is the content updated frequently, the last update statement being displayed in a prominent place? } \\
\text { o Does the site display only information that is relevant for its purposes? } \\
\text { O Does the site display only the available content, and is the content suitable to the page length? } \\
\text { o Does the site provide concise and non-repetitive information? } \\
\text { O Is there a link provided to the homepage? Was the site built by a reliable institution? } \\
\text { O Are the reliability, stability and continuity of the site content guaranteed? }\end{array}$ \\
\hline & $\begin{array}{l}\text { Error-free: } \\
\text { Are errors, confirmation, and prompt messages displayed consistently throughout the site? } \\
\text { O Is the site free of typographical errors and spelling mistakes? } \\
\text { o Do error messages prevent potential errors from happening? } \\
\text { o Does the site provide solutions that help the user avoid errors, such as providing 'undo' and 'redo' features? } \\
\text { o Can errors be averted or minimized when possible? } \\
\text { Can corrective action be taken to rectify errors? } \\
\text { Are the details of the error messages available with indication to what actions are that users need to take to correct the } \\
\text { error? }\end{array}$ \\
\hline & $\begin{array}{l}\text { Representation with familiar terminology \& understandable content: } \\
\text { Is the content readable, scannable and easy to understand? } \\
\text { O Do the content blocks need to be visually separated? } \\
\text { Are the vocabulary and terminology used familiar to users? } \\
\text { O Does the site provide correct spelling and grammar, and understandable graphic symbols? }\end{array}$ \\
\hline & $\begin{array}{l}\text { Appropriate \& approachable content: } \\
\text { O Is the organization of the content suitable for achieving the primary goals of the site? } \\
\text { O Are users provisioned with FAQ? } \\
\text { Does the site offer an appropriate amount of information for the page length, and is all the text of a viewable/readable } \\
\text { size? } \\
\text { Does the site provide an icon for help next to a field? } \\
\text { O Does the site show error in different colour and layout to read easily? }\end{array}$ \\
\hline & $\begin{array}{l}\text { Site upload time \& memory utilization: } \\
\text { o Is the site upload-time reasonable? } \\
\text { o Is the site free from heavy coding /unwanted scripting which could consume more time/memory? } \\
\text { o Are response period suitable to the member's cognitive processing? } \\
\text { O Are response period suitable to each task? }\end{array}$ \\
\hline
\end{tabular}




\begin{tabular}{|c|c|}
\hline \multirow[b]{2}{*}{ Security and privacy (SP) } & 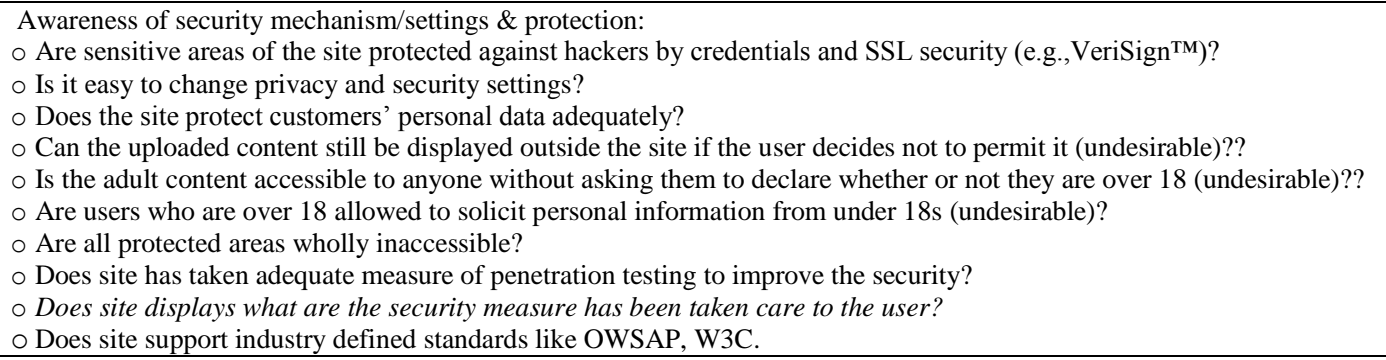 \\
\hline & $\begin{array}{l}\text { Transparency of transactions: } \\
\text { ○ Is the adopted security mechanism and policy clearly displayed? } \\
\text { o Does the site provide transparency of transactions and data use to build user confidence and trust, unless the user gives a } \\
\text { clear indication not to expose it? } \\
\text { o Are links to 'privacy policies' and 'terms \& conditions' clearly displayed? } \\
\text { o Is it clearly stated that any data submitted will not be used for other purposes, in order to build user confidence and trust? } \\
\text { o Are there processes in place to check the number of memberships or access statistic data? } \\
\text { o Should users upload, post, email, transmit or otherwise make available any content that is unlawful, harmful, } \\
\text { pornographic and racial, do other users have the option to report any suspicious activity or inappropriate content that } \\
\text { breaches the terms of service directly to the customer service or site manager? } \\
\text { ○ Does site provide details like what is the user's information are going to be stored? } \\
\text { ○ Does site declares about sharing the user's information to } 3^{\text {rd }} \text { party for any purpose? } \\
\text { ○ Does site informs user to contact for promotion, marketing and others such communication? }\end{array}$ \\
\hline \multirow{6}{*}{ Business support (BS) } & $\begin{array}{l}\text { Advertising or sales pitches mechanism: } \\
\text { ○ Is the advertising experience on the site too intrusive, disturbing the user's primary actions? } \\
\text { o Does the site have pop-up advertisements (undesirable)? } \\
\text { o Does 'multimedia help' make advertising enjoyable/attractive? } \\
\text { o Can users leave comments and "likes" (these are social media terms)? } \\
\text { o Can users classify advertisements easily? } \\
\text { o Do the features of the paid membership are clearly described with giving hot offers? }\end{array}$ \\
\hline & $\begin{array}{l}\text { Trust \& credibility of information sources and company advertising: } \\
\text { o Is the user interested in the advertisement characters because they are drawn from the user's own culture? } \\
\text { o Does the user have confidence that the site is operating in the way it was designed to? }\end{array}$ \\
\hline & $\begin{array}{l}\text { Easy to follow \& share: } \\
\circ \text { Can users share the content easily (text and links)? } \\
\circ \text { Are the videos and photos easy to upload, download, share, retrieve and organise? } \\
\circ \text { Can users share (i.e. post to friends' profiles) and tag other members in photographs and videos. } \\
\circ \text { Are users able to access each other's profile information? } \\
\circ \text { Are users allowed to share their content with other SNS services? } \\
\end{array}$ \\
\hline & $\begin{array}{l}\text { Forum/blog facilities and connectivity with different groups/businesses: } \\
\text { o Do users become engaged with the site through a set of facilities that are designed to promote engagement (e.g. by } \\
\text { creating a group, blog, business)? } \\
\text { o Will information posted on users' walls appear on their fans' walls? } \\
\text { o Is it easy to create polls, pages and forums? } \\
\text { o Are blogs and forums used to get ideas about markets, customers, and strategies? } \\
\text { o Is it easy to use site mail to communicate with friends? } \\
\text { o Is it allowed to make free calls between computers and/or phones? } \\
\text { o Is it easy to create events or select widgets using a calendar? } \\
\text { o Can users join regional, educational or workplace networks? } \\
\text { o Do websites use 'crowdsourcing' approach to stimulate innovation, solving problem and sharing knowledge? }\end{array}$ \\
\hline & $\begin{array}{l}\text { Syndication of Web content (such as RSS tools): } \\
\text { o Is there a news feed on users' home pages that provides them with friends/ company activity updates? } \\
\text { o Can users publish RSS feeds to their profiles? } \\
\text { o Are RSS filters used to create content streams to improve customer relationship management? }\end{array}$ \\
\hline & $\begin{array}{l}\text { Frequent posting \& updating: } \\
\text { ○ Are interactive tools such as post text, single chat and multiple chat provided? } \\
\text { ○ Is it easy to modify, update and remove posts? } \\
\text { o Can the users participate as much as they want? }\end{array}$ \\
\hline $\begin{array}{l}\text { User usability, sociability } \\
\text { and management activities }\end{array}$ & $\begin{array}{l}\text { Manageable personal profile \& user-driven content: } \\
\text { o Is it easy to register on the site? } \\
\text { o In case of theft and/or a forgotten password, is recovery option available? } \\
\text { o Can customers personalise (customise) their online workplace? } \\
\text { o Can users edit/delete the content that they have posted? } \\
\text { o Can users easily collect and access the content that they have found and liked/marked as favourite? } \\
\text { o Can users create and modify their personal profile, and delete it if necessary? } \\
\text { o Reporting mechanism: Can users report content that they may have a problem with (such as sexual, religious, illegal, } \\
\text { etc.) easily? } \\
\text { o Can the network delete a content that has received a lot of complaints? } \\
\text { o Can the user manage all the activities pertaining to the site with ease, and have overall control? } \\
\text { o Are items logically labelled and grouped in a control panel? }\end{array}$ \\
\hline
\end{tabular}




\begin{tabular}{|c|c|}
\hline & $\begin{array}{l}\text { Easy functionality, participation \& user privileges, such as revoking \& accepting friends/connections: } \\
\text { o Private messaging: Can users who are directly connected chat/ message each other in a private conversation? } \\
\text { o Public messaging: Can users broadcast and share messages with other users with whom they are directly connected? } \\
\text { o Is it easy to accept new friends and blocking unwanted friends/connections? } \\
\text { o Can users choose who they want to be directly connected to? This should be a two way agreement - where both users } \\
\text { approve of the connection. } \\
\text { o Can a conversation take place between more than just } 2 \text { users? } \\
\text { o Can users register a group or book or band? Can they create a fan club for a band? }\end{array}$ \\
\hline & $\begin{array}{l}\text { Supporter of users' skills \& freedom, such as the customization of users' content/messaging and notifications: } \\
\text { o Does the site allow the user to initiate actions? } \\
\text { o Can users create their own templates or page graphics? } \\
\text { o Are there enough options for organising page layout or templates? } \\
\text { o Can users choose a number of applications to be displayed on their } \\
\text { profile page? } \\
\text { o Does a website use e-mail notifications to encourage members? } \\
\text { o Does site provides customisation based on users choice? }\end{array}$ \\
\hline & $\begin{array}{l}\text { Offers of informative feedback - action \& reaction: } \\
\text { o Is there confirmation for each action? } \\
\text { o Is feedback given in proportion to the action performed (not too much and not too little)? } \\
\text { o Are errors conveyed in context and written in a way that users will understand? } \\
\text { o Does the site provide an overview of the work process that has been completed by the user (e.g. completing a user's } \\
\text { profile)? } \\
\text { o Is the feedback given at any specific time tailored to the content or problem being studied by the user? } \\
\text { Does the site feedback provide the user with meaningful information concerning their current level of achievement } \\
\text { within the program? } \\
\text { o Is the message of current status related to the user's task? } \\
\text { Does the site program provide the user with opportunities to access extended feedback from instructors through email } \\
\text { and internet communication, and are adequate FAQs also offered? } \\
\text { D Does the performance support tools provided mimic their real-world counterparts? }\end{array}$ \\
\hline & $\begin{array}{l}\text { Appropriate multimedia with complete user control: } \\
\text { o Are the videos and images on the site of high quality, with the inclusion of alternative text for visually impaired people? } \\
\text { o Can users change video, audio and image settings easily? } \\
\text { o Is a mechanism provided to skip/stop animation and video without disruption? } \\
\text { o Does the site include sound and visual effects, these effects providing meaningful feedback or hints, designed perhaps to } \\
\text { stir particular emotions? } \\
\text { o Does the site include surprises, humour and interesting representations for the user, while avoiding unnecessary } \\
\text { multimedia representations that could confuse a user who has just started to work with the site? } \\
\text { o Is there unnecessary animation and 'flash' on the site (undesirable)? } \\
\text { o Is it easy for users to set up their own channels (e.g. YouTube channels)? } \\
\text { o Are video ratings and comments available on the site? } \\
\text { o Can users modify photo, audio and video submissions? } \\
\text { O Are users allowed to play videos outside the site (e.g. YouTube) which would mean that they could be 'embedded' into } \\
\text { other websites? }\end{array}$ \\
\hline \multirow{3}{*}{$\begin{array}{l}\text { Accessibility and } \\
\text { compatibility }\end{array}$} & $\begin{array}{l}\text { Accessibility and compatibility of hardware devices: } \\
\text { O Is the site compatible with various platforms and hardware, and can its features be adapted to individual user } \\
\text { preferences? } \\
\text { o Do potential users have to have special computer skills to be able to use site? } \\
\circ \text { Are all the input devices/buttons that have no function disabled to prevent user-input errors? } \\
\circ \text { Are the lessons accessible to users with physical impairments, and their contents available in various languages? } \\
\text { o Does the site is properly load tested and support agreed number of users at a time. } \\
\text { o Does the site have proper Disaster Recovery in place? } \\
\text { o Does the site is supported by text reader or other such devices? }\end{array}$ \\
\hline & $\begin{array}{l}\text { Accessible path-contact details, help and support: } \\
\text { o Is a site map and /or table of contents available, as well as a calendar? } \\
\text { o Is there accessible and appropriate help available on demand? } \\
\text { o Does the site provide clear contact details, using multiple contact formats (email, forms, etc.)? } \\
\text { o Is the FAQ page easy to find? } \\
\text { o Is everything on the site clearly understandable by the user, including how to access options for additional guidance } \\
\text { (chatting, editing, adding, seeking instruction or other forms of assistance) when needed? } \\
\text { o Does user allowed to resume work where they left off after getting help? } \\
\text { o Does the performance of the site is satisfactory and it loads most of the content in less than a second? }\end{array}$ \\
\hline & $\begin{array}{l}\text { Easy access through universal design: } \\
\text { o Has a universal design been implemented to cater for diversified user groups? } \\
\text { o Is the structure too tight (strangling) or too loose (lacking cohesion), both of which are undesirable? }\end{array}$ \\
\hline \multirow[t]{2}{*}{$\begin{array}{l}\text { Navigation site and search } \\
\text { quality }\end{array}$} & $\begin{array}{l}\text { Correct \& reliable navigation/directions: } \\
\circ \text { Do all links and buttons lead to the correct location? } \\
\circ \text { Does the site provide a breadcrumb (cookie crumb trail) to identify the path to the current location? } \\
\text { o Does the site match the menu structure to the task structure, and can the user distinguish between options and content on } \\
\text { the pages? }\end{array}$ \\
\hline & Easy identification of links and menus: \\
\hline
\end{tabular}


O Are the navigation objects and tools placed in consistent, clearly defined positions, and are they of an adequate size? o Are icons and links labelled?

o Is an item still visible when it should be hidden from view, and vice versa?

O Are the menus straightforward and easy to understand, the items being logically grouped and labelled? Do buttons, links and features have a 'mouseover' or pop-up window that provides meaningful feedback?

Search support \& functionality:

o Are the functionality of buttons and controls obvious from their labels or from their design?

o Are there clearly visible search buttons and search input fields consistently placed across all pages?

Are there live search results and filtering?

o Does site help to auto fill the search query?

Does the search response are fast enough?

o Are the results of searches clear, visible, informative, advisable and relevant?

- Does the site support different search criteria (e.g. groups, people, interests, content, suggestions, and companies)?

o Does the results page show the user what was searched for, and is it easy to edit and resubmit the search?

- Are all the necessary functions of the site available without having to leave the site, and do they work correctly?

- Are all the functions clearly labelled, thus facilitating successful completion of the task? Is the status of each task made clear on every page?

$\circ$ Is the search engine accurate?

○ Does the site support onsite searches within country/region, language, interests, industry, keyword videos, channels, play lists, and groups?

o Can the moderated or restricted content be viewed by members with "SafeSearch" switched on? 